\title{
USING TQM to ImPLEMENT SUSTAINABILITY in Supply Chain Management
}

\author{
Lynn A. Fish
}

A web appendix for this paper is available at:

http://dx.doi.org/10.15239/j.brcacadjb.2016.06.01.wa02

Lynn A. Fish, Ph.D.

Associate Professor of Management

Wehle School of Business

Canisius College. 2001 Main St., Buffalo, NY 14208.

Email: fishl@canisius.edu.

Telephone: (716) 888-2642.

\begin{abstract}
Through a literature review, research supports using Total Quality Management (TQM) as a potential framework to implement sustainability in Supply Chain Management (SCM). The research highlights Total Quality Management (TQM) philosophies of a customer focus, continuous improvement and cultural shift necessary to implement sustainability. The relationship between sustainability and Quality gurus' philosophies, TQM approaches and tools are developed. This framework offers practitioners best
\end{abstract}


practices and known tools and techniques to implement sustainability and avenues for future research for academics.

Keywords: Sustainability, Total Quality Management, Supply Chain Management

\section{INTRODUCTION}

Throughout history, in order to remain in business managers have met customer's requirements. Following World War II, the Japanese incorporated quality management into their systems. By the 1980's, due to the Japanese influence, quality was the competitive priority demanded in the marketplace. U.S. and European managers adopted quality management systems and the concept of Total Quality Management (TQM) to address this need. By the 1990's, companies needed to address time competition and waste reduction, and the Just-In-Time (JIT) and lean production philosophies assisted managers to meet these requirements. As the $21^{\text {st }}$ century began competition was no longer company versus company, but rather, supply chain versus supply chain. Managers needed to address the integration aspects demanded by Supply Chain Management (SCM) - and more specifically the complex, global SCM. Today, global environment and humanitarian concerns are highlighted in news headlines, and managers must address sustainability issues with their products and processes. Since companies that do not develop new products or services will ultimately cease to exist, managers always need to manage the development chain as well. In short, today's managers need to simultaneously address SCM, TQM, JIT, globalization, the development chain - and now, sustainability. This is a complex undertaking!

What frameworks, tools and techniques can managers use to address sustainability? Research highlights the lack of management systems or frameworks to support organizations to achieve their sustainability objectives in a systematic and continuous way (Delai \& Takahashi, 2013). However, as the literature review below demonstrates, the philosophy, 
tools and techniques of TQM have been used to address sustainability requirements in SCM. In the discussion, we propose using TQM more fully as a framework to support sustainability in SCM.

\section{DEFINITIONS AND RELATIONSHIPS}

Since various definitions exist for key concepts, we begin by defining key terms and concepts. The development chain includes idea generation, market research, product design and development phase, sourcing decisions, and production plans. During the plan/design phase, decisions on the product architecture, make versus buy and early supplier involvement are made. The sourcing phase follows and addresses supplier selection and contracts, and potential strategic partnerships. In order to remain competitive, supply chains must continuously develop and deliver new products and services to the marketplace (Simchi-Levi, Kaminsky \& Simchi-Levi, 2013).

Simply put, quality can be defined as meeting or exceeding customer expectations (Evans \& Lindsay, 2002). Total Quality Management (TQM) is a management philosophy whereby all management principles and practices can develop from the belief that the continual improvement of quality is the key to success (Deming, 1986). TQM is a philosophy that stresses three principles for achieving high levels of process performance and quality: customer satisfaction, employee involvement and continuous improvement (Krajewski, Ritzman \& Malhotra, 2013). Employee involvement, which encompasses changing the organizational culture, encouraging teamwork and empowering employees, and continuous improvement through various techniques to continually improve processes, support the critical focus on customer satisfaction. Quality leaders, such as Philip B. Crosby, W. Edwards Deming, Joseph M. Juran, Armand Feigenbaum, and Genichi Taguchi, developed methods to improve quality throughout the organization and build a culture of continuous improvement focused on the customer (APICS, 2010). Key TQM concepts include continuous improvement through the Deming Wheel, Six Sigma Quality 
and DMAIC, employee empowerment, benchmarking, JIT, Taguchi Concepts, and various TQM tools (Heizer \& Render, 2014). Quality tools exist and include, but are not limited to: cause analysis tools (cause-andeffect diagrams, Pareto charts, and scatter diagram), evaluation and decision-making tools (decision matrix and multi-voting), process analysis tools (flowchart, failure modes and effects analysis, mistake-proofing, and spaghetti diagrams), data collection and analysis tools (box and whisker plot, check sheet, control chart, design of experiments, histogram, scatter diagram, stratification, and surveys), idea creation tools (affinity diagram, benchmarking, brainstorming, and nominal group technique), an project management tools (Gantt chart and Plan-Do-Check-Act continuous improvement model), and other process management tools (relations diagram, tree diagram, matrix diagram, L-shaped matrix, arrow diagram, and process decision program chart) (Tague, 2004).

SCM is the design, planning, execution, control and monitoring of the global network used to delivery products and services from raw materials to end customers through engineered flows of information, physical distribution and cash (APICS, 2010). The objective of SCM is to create net value, build a competitive infrastructure, leverage worldwide logistics, synchronize supply and demand, and measure global performance. SCM is an approach to integrating suppliers, manufacturers, distributors and retailers, such that products are produced and distributed at the right quantities, to the right location, at the right time, with the mutual goals of minimizing system wide costs and satisfying customer service requirements (Simchi-Levi et al., 2008). Key supply chain processes include product design, production, delivery, support, supplier-customer relationship management, and reverse logistics. Supply chains compete based upon cost, quality, time and responsiveness. Supply chain improvement tools include, but are not limited to process improvement tools of flow charting, flow diagrams, service blueprints, process analysis, process re-engineering, link charts, multi-activity analysis, backward chaining, and Gantt charts. 
SCM and TQM are integrated through Supply Chain Quality Management (SCQM), which is a systems-based approach to performance improvement that integrates supply chain partners and leverages opportunities created by upstream and downstream linkages with a focus on creating value and achieving satisfaction of intermediate and final customers (Foster, 2008; Robinson \& Malhotra, 2005). SCQM combines TQM practices (particularly top management commitment, customer focus, training and education, continuous improvement and innovation, supplier management, and employee involvement (Talib, Rahman \& Quereeshi, 2010; Talib \& Rahman, 2010) with SCM practices: customer relationship, material management, strategic supplier partnerships, information and communication technologies, corporate culture and close supplier partnerships (Tan, 2001; Koh et al., 2007). In SCQM, the six TQM areas that are related to supply chain performance are leadership, strategic planning, human resources management, supplier quality management, customer focus, and process management (Azar, Kahnali \& Taghavi 2010). Several cases to support supply chain improvement through SCQM exist (Fish, 2011).

The Brundtland's Report defines sustainability as 'a development that meets the needs of the present without compromising the ability of future generations to meet their own needs' (World Commission on Environment and Development, 1987, p. 43). Sustainability is often conceptualized as a framework for aligning the 'triple bottom line' (TBL) - environment, social and economic dimensions (Asby, Leat \& Hudson-Smith, 2012), also referred to as 'people, planet, profits'. Environmental sustainability, which includes pollution and global warming (that can be attributed to 6 greenhouse gases), is the most recognized dimension of sustainability as corporations seek to reduce the natural resource consumption below the natural reproduction for the products that are produced and processes that are used. Social sustainability addresses companies' relationship with their main stakeholders: employees, community, public sector, suppliers and customers (Delai \& Takahashi, 2013), and can be divided into internal (motivation, skills, and loyalty of employees and business partners in the 
supply chain) and external (value that is added to the community that the company operates in). Social sustainability is the least researched and developed dimension (Gmelin \& Seuring, 2014; Beske, Land \& Seuring, 2014). While companies are starting to recognize the need to address social sustainability and the concept of social sustainability is growing (Vachon \& Mao, 2008), many managers feel that social sustainability efforts are more difficult to measure and results may be intangible. Economic sustainability refers to the profitability of the sustainable efforts. Without economic sustainability, businesses will cease to exist, and therefore, economic viability is a requirement in order to remain in business. Many business theories view the three dimensions as tradeoffs and not necessarily 'win-win' situations (Porter \& van der Linde, 1995). Most sustainability studies focus on environmental factors over social factors and examples of corporations and associated supply chains demonstrating integration of all three extremely rare (Asby et al., 2012; Ozcelik \& AvciOzturk, 2014).

SCM and sustainability have been integrated through a field known as Sustainable Supply Chain Management (SSCM). SSCM can be defined as the management of material, information and capital flows through cooperation among companies along the supply chain while addressing goals from all three dimensions of sustainable development (economic, environmental and social), which are derived from customer and stakeholder requirements (Seuring \& Muller, 2008). Companies can gain competitive advantage through sustainability (Campbell, 2007). SSCM includes evaluation of the environmental impact, a multi-disciplinary perspective of the entire product life-cycle, and considerations for all stages across the entire value chain for each product (Gupta \& Palsule-Desai, 2011). Top management commitment, a supportive culture, employee involvement, cross-functional teams, enhanced communication, adopting environmental management systems, and cooperation with suppliers enable SSCM (Ozcelik \& AvciOzturk, 2014). 
In another integration of concepts, environmental sustainability and TQM have a positive association through a framework known as Total Quality Environmental Management (TQEM) (Curkovic, Melnyk, Handfield \& Calantone, 2000; Curkovic, Sroufe, \& Landeros, 2008; Corbett \& Klassen, 2006). The same processes that improve quality, reduce waste, cut costs and improve competitiveness are used to improve environmental outcomes (Curkovic et al., 2000). TQEM efforts start by gathering easily changed items, such as reducing energy use, and then moves on to examining more fundamental issues, such as supply chain design and business models, that require further environmental action with significant investment, radical changes in operational practices and reengineering of existing supply chains (Devinney, 2009).

This discussion has clarified specific frameworks and concepts that will be used to develop the framework for implementing sustainability in SCM. It also highlights the integration of key concepts over time. Firms are increasingly required to offer high quality, innovative products at competitive prices, and to develop supply chains that are sustainable in the long run (Gupta \& Palsule-Desai, 2011). In order to remain competitive, today's managers must integrate sustainability efforts with quality, supply chain and development efforts in order to meet the end customer's requirements. We continue by discussing the commonalities between sustainability and SCQM.

\section{SUSTAINABILITY \& TQM}

Literature contains common themes and concepts between TQM and sustainability implementation in supply chains. We continue by discussing the commonalities between sustainability and TQM principles of customer satisfaction, employee involvement and continuous improvement, consider Cost of Quality and Quality Gurus' philosophies as they relate to sustainability, and then highlight examples of where TQM concepts and tools were used to implement sustainability. 


\section{Customer focus}

In general, the push to incorporate quality into products in the 1980's in western countries arose as Japan entered the global markets with products that focused on the end customer's requirements. Governments responded to encouraging companies to meet the quality requirements through regulations and programs, such as the Malcolm Baldrige Award (in the U.S.) and ISO-9000 (quality management system). Good quality has a positive impact upon a company's reputation, while poor quality may increase product liability costs. Quality is a 'global' requirement as products must meet customers' global quality, design and price expectations (Heizer \& Render, 2014).

Today, the need to address sustainability arises from several different areas, including: global resource depletion and raw material scarcity, stakeholder demands for information and accountability, consumer's concerns, the deterioration of human rights, and government policies and regulations (Beske et al., 2014; CEOForumGroup, 2009; Seuring, 2004). Similar to quality, sustainability can be positively related to company reputation (Driessen, Hillebrand, Kok, \& Verhallen, 2013), and failure to meet sustainability requirements may lead to a company not being selected as a supplier. Today, sustainability is a global requirement. For example, the European Union (EU) current and future legislation focuses on creating regulations requiring sustainability integration - similar to the EU requiring ISO9000 in the past, which increased the global pressure to implement quality (Buyukozkan \& Berkol, 2011). ISO14000 (environmental sustainability) and ISO26000 (social sustainability) encourage global sustainability efforts (Gmelin \& Seuring, 2014). Many companies require their suppliers to meet these standards in their supplier certification programs. For example, Walmart's supplier sustainability assessment covers 15 questions that include supplier information on energy and climate (reducing energy costs and greenhouse gas emissions), material efficiency (reducing waste and enhancing quality), natural resources (producing high quality, responsibly sourced raw materials) and people and community (ensuring responsible and ethical production) (Walmart 
Supplier Sustainability Assessment, 2013). With respect to sustainability, customer satisfaction may be assessed through surveys, customer health and safety can be impacted upon through health and safety production standards, quality and safety level control can be through monitoring internal supply chain members, and products, labeling and customer sustainability education (for example, through recycling stations, ecobags and sustainability store communication) can drive sustainability awareness. Hence, we conclude that society - and customers are seeking sustainable products, services and processes.

\section{Cultural Shift (Empowered Employees \& Top Management Commitment)}

Implementing quality through TQM required a cultural shift that included top management support and value-added, empowered workers and teams. Deming, Juran and Crosby's philosophies require top management commitment to quality, holding top management responsible for the system (Evans \& Lindsay, 2002). Similarly, a best practices in implementing sustainability in SCM is top management support and commitment (Delai \& Takahashi, 2013; Fish, 2015; Ozcelik \& AvciOzturk, 2014). Top management needs to define a sustainability mission, strategy, scope, targets, and processes (Allen, Walker \& Brady, 2012; Delai \& Takahashi, 2013), so that a culture to foster sustainability develops and supports the strategy, which is linked to relevant performance metrics and reports (Delai \& Takahashi, 2013; Fish, 2015; Sroufe \& Melnyk, 2013). Top management must strategically align the organization and its associated supply chains toward delivering sustainable products and services. Sustainability is a system opportunity (Sroufe \& Melnyk, 2013) as waste is ultimately linked to processes (Sroufe \& Melnyk, 2013). The approach a company uses to manage sustainability reflects its priority and the degree that sustainability is embedded in the organizational procedures, and another demonstration of a commitment to sustainability is having a high level position for promoting and guiding sustainability efforts (Delai \& Takahashi, 2013). For example, Nike integrated sustainability 
and innovation initiatives through an organizational structure where the vice president, who reports directly to CEO, is charged with sustainability and innovation efforts (McCarty, Jordan \& Probst, 2011). The end-result is that top management is responsible for sustainability efforts.

TQM is founded on a cultural shift within the organization the treats workers as value-added resources through training and an organizational structures that encourage and promote participation in continuous improvement. Similarly, developing a workforce that treats employees as value-added assets is a best practice that can assist in sustainability efforts (Fish, 2015; Ozcelik \& AvciOzturk, 2014). A workforce, committed to continuous improvements and innovation, and sustainability can mitigate trade-offs between short term profitability and long term sustainability goals (Wu \& Pagell, 2011). Training employees in sustainability provides a competitive advantage over other suppliers (Allen et al., 2012; Delai \& Takahashi, 2013). It is essential that the culture of the organization support sustainability efforts.

\section{Continuous Improvement}

In TQM, continuous improvement is founded on a philosophy of continually seeking ways to improve processes, typically through Deming's Wheel. The Deming (or Shewhart) circle promotes a process of 'PlanDo-Check-Act' that identifies problems, plans improvements, tests the plan, studies whether the plan is working, acts to standardize the positive tested plan, and then, returns to plan additional improvements. Using a TQM mentality to implement sustainability allows companies to focus on process-thinking and root causes, correcting the problems, perpetual improvement, problem identification, and then taking action to bring about positive results (Sroufe \& Melnyk, 2013). Continuous improvement can be used to drive sustainability efforts.

\section{Cost of Quality}

Cost of Quality is a method to categorize the costs of 'doing things incorrectly', and can be grouped into 4 categories: internal failure costs 
(costs associated with defect prior to delivery to a customer), external failure costs (costs associated with defect once the customer receives the product or service), appraisal costs (costs related to evaluating products, services and processes to ensure quality levels are met) and prevention (costs associated with preventing defective parts or services). While sustainability does not currently have corresponding cost categories, SSCM focuses on prevention over correction (Sroufe \& Melnyk, 2013) similar to COQ where prevention methods are preferred. People perceive trade-offs between economic, environmental and social sustainability to exist as environmental or social sustainability costs may be significant and potentially negatively impacting upon economic viability $(\mathrm{Wu} \&$ Pagell, 2011). For example, a retrofitted building may carry positive environmental benefits (smaller footprint and less energy); however, the expense may be unjustifiable (Wu \& Pagell, 2011). Other cases demonstrate a positive relationship between sustainability and financial performance in increasing profitability and reducing waste, energy, material and water expenses (Willard, 2012). The SSCM system should encourage innovative cost neutrality or economically viable solutions that are more environmental sustainable in the long term (Wu \& Pagell, 2011). Extending the COQ categories to sustainability can assist in reporting and monitoring sustainability efforts.

\section{Quality Gurus}

The philosophies of the world-renown quality gurus', W. Edwards Deming, Joseph Juran, Philip Crosby, Armand Feigenbaum, and Genichi Taguchi, can be used to implement sustainability as noted in Table 1 . As noted previously, Deming's philosophy formed the basis for TQM, requires top management support and a cultural change towards continuous improvement. Juran defines quality as 'fitness for use' and focused on 'form, fit and function' in product and services. Juran observed that all breakthroughs follow a universal pattern that can be transferred to sustainability implementation (Sroufe \& Melnik, 2013). Juran's universal pattern includes proof of need (metrics), project identification (Pareto 
analysis), an organization to guide the breakthrough (sustainability team lead by upper management), diagnosis (analysis of symptoms) remedial action (take action, measure and deal with resistance to change by using metrics to align business case with sustainability goals), breakthrough cultural resistance and control at the new level. By using the breakthrough approach fostered by Juran, best practices approaches to sustainability can improve its profitability and revenues, avoid profit erosion, reduce energy, waste, materials and water expenses, increase employee productivity, reduce hiring and attrition expenses and reduce strategic and operational risks (Willard, 2012). Crosby's basic philosophy addressed quality being led by top management; however, he focused on a different culture - that is western (US and European) versus eastern (Japan) and developed a 14-step approach to develop a quality system and culture that fit with the western culture. This brings up a critical point: a system to address sustainability should take into account the culture of the people. Similar to Juran's financial analogy, Crosby's philosophy highlights the need for appropriate measures to promote sustainability. Feigenbaum is best known for his 40 steps to quality improvement, which can be used to implement a quality management system. His work on cross-functional teamwork is related to the need for teams to implement sustainability. Specifically, cross-functional collaboration among departments is a success factor for sustainability (Petala, Weaver, Dutilh \& Brezet, 2010), and may include internal organizational integration as well as inter-firm (external) collaboration (Homburg \& Kuehnl, 2014). Taguchi's philosophy encourages improved product and process quality through removing adverse conditions. His philosophy of target-oriented quality encourages a philosophy of continuous improvement toward bringing a product exactly on target. Correspondingly, sustainability efforts should be focused on 'thinking outside the box' and 'removing adverse' conditions through carefully defining the system's scope and defining clear sustainability metrics. As the discussion here highlights, quality management philosophies can be used to direct sustainability implementation. 


\section{TQM Approaches \& Sustainability.}

We continue our discussion by reviewing quality approaches that have been applied to sustainability efforts and highlight specific case examples where the approach has been used. Typical TQM approaches include: Continuous Improvement and Employee Empowerment (both discussed previously), benchmarking, Six Sigma Quality (DMAIC and DMADV), and JIT. Table 2 outlines each TQM approach as it applies to sustainability.

Benchmarking. Benchmarking, or the search for industry best practices that lead to superior performance, promotes a focus on processes and adaptation of other processes that work elsewhere to improve processes. Benchmarking can be used to assess and monitor sustainability performance (Sroufe \& Melnyk, 2013), and provides a comparative analysis of the product by taking into account best competitors in the same market share (Fargnoli \& DeMinicis, 2014). As an example of incorporating benchmarking into sustainability decision-making, a Medical products manufacture chose DuPont, which uses a 'phased gate approach' to integrate sustainability into NPD (Sroufe \& Melny, 2013). DuPont uses a sustainability index that assesses products over 11 different criteria (Sroufe \& Melnyk, 2013). SCOR, a SCM performance measurement system, ties emissions to processes that provides a structure for measuring environmental performance and assists in identifying where performance can be improved (Sroufe \& Melnyk, 2013). The SCOR model can be used to assess the strategic environmental and through mapping, develop activities to address the gaps (Sroufe \& Melnyk, 2013).

Six Sigma Quality. Six Sigma is a comprehensive, flexible system for achieving, sustaining and maximizing business success by minimizing defects and variability in processes (Krajewski et al., 2013). Some researchers view Six Sigma Quality as having a different focus than TQM (Krajewski et al., 2013), while others view Six Sigma Quality as a key concept in a TQM program (Heizer \& Render, 2014). We adopt the latter philosophy here, and treat Six Sigma as a value-added approach to addressing quality - and sustainability implementation. Six Sigma Quality 
is a strategy that focuses on total customer satisfaction, follows the formal six sigma process known as DMAIC and uses seven tools to improve quality (check sheets, scatter diagrams, cause-and-effect diagrams, Pareto charts, flowcharts, histograms and statistical process control). Six Sigma Quality can be used to focus on customer sustainability requirements through data-driven decision-making, risk assessment, critical inputs, processes and outputs (McCarty et al., 2011).

DMAIC. The five-step improvement process, DMAIC (Define, Measure, Analyze, Improve and Control) can be applied to sustainability analysis. In the 'Design' phase, the team identifies the improvement opportunity, understands the task and problem, develops the problem statement, identifies critical customers' requirements, and determines the critical processes. The team is assigned, and develops its team charters, stakeholder analysis, 'Voice of the customer', process maps and barriers through flowchart and value stream analysis. During the 'Measure' phase, relevant sustainability data is collected and provides a product/ process baseline. Tools useful during 'measure' include flowcharting, benchmarking, check sheets, and graphing. During the 'Analyze' phase, the true root causes of the sustainability problem that lead to customer dissatisfaction are determined through root cause analysis, statistical analysis, cause-and-effect diagrams, and control charts. In the 'Improve' phase, solutions are identified, evaluated and selected to correct and fix the root cause. Improvement tools include brainstorming, Failure Modes and Effects Analysis, and simulation, as well as a plan to address organizational changes to implement the solution. In the final phase, 'Control', actions and tools are implemented to keep the processes operating appropriately (including process documents and training records), results are disseminated, an ongoing monitoring and reporting plan is implemented, and metrics are gathered to demonstrate improvement.

A variation of DMAIC, DMADV can also be used to implement sustainability. DMADV requires a project champion, a black belt, a project charter and team functional experts. In DMADV, the process begins 
through 'Defining' project goals and customer (internal and external) deliverables. Then, the process moves on to 'Measuring' and determining customer needs and specifications. Followed by, 'Analyzing' the process options to meet the customer needs, 'Designing' development for the process to meet customer needs, and 'Verifying' design performance and ability to meet customer needs. Apex used the DMADV method to develop a Corporate Sustainability Program and to analyze a paper recycling process (McCarty et al., 2011).

JIT. JIT is a continuous improvement philosophy that is designed to produce products just as they are needed. JIT requires a quality management system to be effective. Specifically in a JIT system, quality must be designed into the products and processes, good quality raw materials must be used, and the employees must be empowered with the proper working equipment, tools, training, support and encouragement. One of JIT's focus is to remove non-value added processes and waste. Similarly, SSCM focuses on products, processes and packaging as sustainability efforts must be addressed in strategic, tactical and operational performance (Sroufe \& Melnyk, 2013). SSCM considers waste as a symptom, not the root cause, links waste to processes, and considers waste management and elimination to be economically driven.

\section{TQM Tools \& Sustainability.}

Several quality tools were used to implement sustainability in SCM, as shown in Table 3. (Note: Table 3 is an overview and not intended to represent sustainability usage for every TQM tool.) Quality tools include, but are not limited to, affinity analysis, brainstorming, cause-and-effect analysis, check sheets, histograms, House of Quality (HoQ), Plan-DoCheck-Act Wheel, Pareto Analysis, process capability analysis, process control charts, process flow analysis, scatter diagrams, quality at the source, Quality Function Deployment (QFD), Quality and Environment Function Deployment (QEFD), Green Quality Function Deployment (G$\mathrm{QFD})$, and value stream mapping, 
While the intent is not to review each tool in depth, we will review a few to demonstrate the correspondence from quality to sustainability. With Process Flow Analysis, six steps are used to evaluate the effectiveness of a process with respect to quality. To use process flow analysis for sustainability (Sroufe \& Melnyk, 2013): (1) Determine desired sustainability outcome for the entire process and the associated sustainability metrics needed to evaluate the process's performance. (2) Identify and bound the critical process to focus efforts. (3) Document the sustainability for the existing process (to determine 'the current state' map). (4) Analyze the process and prioritize opportunities for improvement. (5) Recommend appropriate changes to the process (towards achieving the 'future state' map). (6) Implement the changes and monitor sustainability improvements.

One of the most commonly used TQM tools for sustainability integration is QFD. A literature review demonstrates the evolution of QFD in SSCM, particularly for NPD and process evaluation (Buyukozkan \& Berkol, 2011). Green-QFD (that incorporated environmental requirements in NPD) was improved upon through a process noted as Green-QFD II by combining it with Life Cycle Analysis (LCA) and life cycle costing, which provided a mechanism to deploy customer, environmental, and cost requirements throughout the entire product development process (Zhang, Wang \& Zhang, 1999). Similarly, researchers incorporated environmental sustainability in a process noted as QFD for Environment (QFDE), which is a four-phase method used in design for the environment in the early stages of NPD (Masui, Sakao, Kobayashi \& Inaba, 2003). Later this method was extended further by integrating LCA and the theory of inventive problem-solving into QFD (Sakao, 2007). Other researchers documented a four-phase methodology using QFD that included an ecoprofile strategies and analytical hierarchy processes (Reyes \& Wright, 2001). Another research team incorporated Taguchi experimental design and the Taguchi loss function into QFD process to assist in NPD (Madu, Kuel \&Madu, 2002). Yet another research team introduced an approach for identifying environmental improvement options by taking customer 
preferences into account and included LCA and a fuzzy approach based on the House of Quality (Bovea \& Wang, 2003). Environmental sustainability was considered through a different method that developed an ecoquality function deployment (Eco-QFD) to aid a product design team in considering environmental concerns (Kuo et al., 2009). Several variations of sustainable QFD (sQFD) exist that mainly incorporate environmental factors into the NPD process (e.g. one applies an analytic network process (ANP) combined with fuzzy logic in QFD (Lin, Cheng, Tseng and Tsai, 2010); another used a sustainable concept comparison house (Halog, 2004), and another applied QFD to improving sustainability in Norwegian fishing fleet (Utne, 2009)). Another applied group applied QFD with ANP and zero-one goal programming to determine design requirements to achieve SSCM for a company in the fuel sector of energy (Buyukozkan \& Berkol, 2011). In a more recent variation of QFD, researchers redesigned a garden trimmer - but included social and environmental sustainability in their analysis (Fargnoli \& DeMinicis, 2014). Obviously, QFD has been used to incorporate sustainability in NPD; but researchers are still developing methods to address all of their needs, particularly social sustainability.

\section{DISCUSSION}

We began this paper by reviewing the key concepts of quality, sustainability and supply chains. While we noted much of the integration of key concepts - TQM with SCM yielding SCQM, and sustainability with SCM resulting in the field of SSCM, a framework to integrate sustainability, quality, and global SCM does not exist in literature today. Therefore, we began our discussion by reviewing the similarities between TQM and sustainability in SCM. The literature review of TQM and sustainability demonstrates the strong similarities between implementing quality and sustainability into a supply chain. The three main TQM principles customer focus, employee involvement (that is, an organizational culture change) and a continuous improvement - are relevant to implementing sustainability as well. There is a call by society and its customers for 
sustainable products, services and processes to address economic, environmental and social sustainability concerns. The organizational culture must promote sustainability efforts, and employees must be given the knowledge and tools to empower them to make sustainability changes. The culture must encourage continuous sustainability efforts throughout the organization, so more than 'just the low hanging' easily implemented sustainability efforts are undertaken. Similar to implementing quality over 30 years ago, implementing sustainability requires support and a cultural change.

Regardless of a company's efforts to implement social or environmental sustainability into the supply chain processes, sustainability does not exist if the company is not profitable (Wu \& Pagell, 2011). Traditional accounting practices do not facilitate TBL sustainability efforts (Ageron et al., 2012). This paper highlights the similar goals to emphasize prevention costs in both quality and sustainability exists. Researchers can assist practitioners to develop a corresponding 'Cost of Sustainability' framework to assist in reporting and monitoring, as well as encourage sustainability efforts.

A review of the quality gurus' philosophies demonstrates the potential to apply the quality philosophies to sustainability implementation. Regardless of which philosopher's system is used, the underlying principle is to change the culture - from top management through the employees to the supply chain members.

Review of TQM approaches (benchmarking, continuous improvement, employee empowerment, Six Sigma quality, and JIT) indicates that these approaches have been used in sustainability efforts already. A general review of TQM tools indicates that many tools have been used in sustainability efforts as well. In particular, many versions of QFD exist to assist with evaluation and incorporation of sustainability into NPD. The literature review, while not comprehensive, supports the use of TQM - and possibly, the broader SCQM principles - to implement sustainability in SCM. 
For the practitioner, this highlights that the framework and techniques to implement sustainability are ones that most already know - that is, quality management approaches and techniques can be applied and assist in sustainability implementation. Managers - particular top management, should develop the strategy, vision, mission, and goals to drive sustainability, provide appropriate resources, and monitor the sustainability efforts through appropriate performance measures (Fish, 2015; Gupta \& Palsule-Desai, 2011). Some of the best practices discussed here to support these efforts include an organizational change with a top level manager charged with sustainability efforts, providing sustainability training to employees of the organization - and possibly suppliers' employees, cross-functional teams, enhanced communication, encouraging supply chain partnerships through supplier certification programs that include sustainability, using environmental management systems, and developing visible, transparent and accurate practices and reports on sustainability efforts and disseminating this information to the supply chain and end customers (Fish, 2015; Ozcelik \& AvciOzturk, 2014). Much work remains to develop a comprehensive framework to extend these basic principles into the real world. Academics can continue to assist practitioners by fully developing a 'Sustainable Supply Chain Quality Management' (SSCQM) framework.

\section{REFERENCES}

Ageron, B., Gunasekaran, A. \& Spalanzan, A. (2012). Sustainable supply chain management: An empirical study. International fournal of Production Economics, 140(1), 168-182. http://dx.doi.org/10.1016/j.ijpe. 2011.04.007

Allen, M.W. Walker, K.L., \& Brady, R. (2012). Sustainability Discourse within a Supply Chain Relationship: Mapping Convergence and Divergence. Fournal of Business Communication. 49(3), pp. 210-236. http://dx.doi.org/10.1177/0021943612446732 
APICS Dictionary (2010). APICS Dictionary: Thirteenth Edition. APICS The Association for Operations Management, Chicago, Illinois. ISBN: 978-0-615-39441-1.

Asby, A., Leat, M. \& Hudson-Smith, M. (2012). Making connnections: A review of supply chain management and sustainability literature. Supply Chain Management: An International fournal, 17(5), 497-516. http://dx.doi.org/10.1108/13598541211258573

Azar, A., Kahnali, R.A., \& Taghavi, A. (2010). Relationship between Supply Chain Quality Management Practices and their Effects on Organisational Performance. Singapore Management Review, 2010 1st Half, 32(1), 45-68.

Beske, P., Land, A., \& Seuring, S. (2014). Sustainable supply chain management practices and dynamic capabilities in the food industry: A critical analysis of the literature. International fournal of Production Economics, 152, 131-143. http://dx.doi.org/10.1016/j.ijpe.2013.12.026

Bovea, M.D., \& Wang, B. (2007). Green quality function deployment: a methodology for integrating customer, cost and environmental requirements in product design. International fournal of Environ. Conscious Design Manufacture, 12(4), 9-19.

Bovea, M.D. \& Wang, B. (2003). Identifying environmental improvement options by combining life cycle assessment and fuzzy set theory. International fournal of Production Research, 41(3), 595-609. http://dx. doi.org/10.1080/0020754021000033878

Buyukozkan, G. \& Berkol, C. (2011). Designing a sustainable supply chain using an integrated analytic network process and goal programming approach in quality function deployment. Expert Systems with Applications, 38, 13731-13748.

Campbell, J. L. (2007). Why would corporations behave in socially responsible ways? An institutional theory of corporate social responsibility. Academic Management Review, 32(3), 946-967. http:// dx.doi.org/10.5465/AMR.2007.25275684

CEOForumGroup (2009). Engaging external stakeholders: Sustainability performance. Retrieved from http://www.ceoforum.com.au/ 
article-detail.cfm?cid=8981\&t=/Rob-Hogarth-KPMG/Sustainabilityperformance/

Corbett, C.J., \& Klassen, R. D. (2006). Extending the horizons: environmental excellence as key to improving operations. Manufacturing \& Service Operations Management, 8(1), 5-22. http:// dx.doi.org/10.1287/msom.1060.0095

Crosby, P. (1979). Quality Is Free. New York, McGraw-Hill.

Curkovic, S., Melnyk, S.A., Handfield, R.B., \& Calantone, R. (2000). Investigating the linkage between total quality management and environmentally responsible manufacturing. IEEE Transactions on Engineering Management, 47(4), 444-464. http://dx.doi.org/10.1109 $/ 17.895340$

Curkovic, S., Sroufe, R., \& Landeros, R. (2008). Measuring TQEM returns for the application of quality frameworks. Business Strategy and the Environment, 17(2), 93-106.

Delai, I. \& Takahashi, S. (2013). Corporate sustainability in emerging markets: insight from the practices reported by the Brazilian retailers. fournal of Cleaner Production, 47, 211-221. http://dx.doi.org/10.1016 /j.jclepro.2012.12.029

Deming, W.E. (1986). Out of the Crisis. MIT Center for Advanced Engineering Study, Cambridge, MA.

Devinney, T.M. (2009). Is the socially responsible corporation a myth? The good, the bad, and the ugly of the corporate social responsibility. Academy of Management Perspectives, 23(2), 44-56. http://dx.doi.org/ 10.5465/AMP.2009.39985540

Driessen, P.H., Hillebrand, B., Kok, R.A.W. \& Verhallen, T.M.M. (2013). Green New Product Development: The Pivotal Role of Product Greenness. IEEE Transactions on Engineering Management, 60(2), 315-326. doi:10.1109/TEM.2013.2246792

Ernzer, M. \& Birkhofer, H. (2002). Selecting methods for life cycle design based on the needs of a company. Proceedings of the $7^{\text {th }}$ International Conference on Design, Zagreb, 1305-1310. 
Evans, J., \& Lindsay, W. (2002). The Management and Control of Quality, Fifth Edition. South-Western College Publishing, Cincinnati, Ohio.

Fargnoli, M. \& DeMinicis, M. (2014). Design Management for Sustainability: An integrated approach for the development of sustainable products. Journal of Engineering and Technology Management, 34, 29-45. http://dx.doi.org/10.1016/j.jengtecman.2013 .09 .005

Feigenbaum, A.V. (1956). Total Quality Control. Harvard Business Review. Nov/Dec, 34(6), 93-101.

Fish, L.A. (2015). Managerial Best Practices to Promote Sustainable Supply Chain Management and New Product Development. Applications of Contemporary Management Approaches in Supply Chains", ISBN 978-953-51-4197-6, InTech Publisher. http://dx.doi.org/10.5772/59581

Fish, L.A. (2011). Supply Chain Quality Management, Supply Chain Management - Pathways for Research and Practice, Dilek Onkal (Ed.), ISBN: 978-953-307-294-4, InTech Publisher, 25-42. Available from: http://www.intechopen.com/articles/show/title/supply-chainquality-management.

Foster, S.T. Jr. (2008). Towards an understanding of Supply Chain Quality Management. Journal of Operations Management, 26, 461-467. http:// dx.doi.org/10.1016/j.jom.2007.06.003

Gmelin, H. \& Seuring, S. (2014). Determinants of a sustainable new product development. Fournal of Cleaner Production, 69, 1-9. doi:10.1016/ j.jclepro.2014.01.053

Gupta, S. \& Palsule-Desai, O.D. (2011). Sustainable supply chain management: Review and research opportunities. Indian Institute of Management Bangalore Management Review, 23, 234-245. http://dx. doi.org/10.1016/j.iimb.2011.09.007

Halog, A. (2004). An approach to selection of sustainable product improvement alternatives with data uncertainty. Fournal of Sustainable Product Design, 4, 3-19. http://dx.doi.org/10.1007/s10970-006-0002-y

Heizer, J. \& Render, B. (2014). Operations Management, Eleventh Edition, Prentice Hall, Upper Saddle River, NJ. 
Homburg, C., \& Kuehnl, C. (2014). Is the more always better? A comparative study of internal and external integration practices in new product and new service development. Fournal of Business Research, 67, 1360-1367. http://dx.doi.org/10.1016/j.jbusres.2013.08.017.

Krajewski, L.J., Ritzman, L.P., \& Malhotra, M.K. (2013). Operations Management: Processes \& Supply Chains. Pearson Education, Inc., Upper Saddle River, NJ.

Koh, S.C.L., Demirbag, M. \& Bayraktar, E. (2007). The Impact of Supply Chain Practices on Performance of SMEs. Industrial Management \& Data Systems, 107(1), 103-124. http://dx.doi.org/10.1108/0263557071 0719089

Kuo, T.C., Wub, HJ.H. \& Shieh, J. I. (2009). Integration of environmental considerations in quality function deployment by using fuzzy logic. Expert Systems with Applications, 36, 7148-7156. http://dx.doi.org/10 .1016/j.eswa.2008.08.029

Lin, Y.H., Cheng, H.P., Tseng, M.L., \& Tsai, J.C.C. (2010). Using QFD and ANP to analyze the environmental production requirements in linguistic preferences. Expert Systems with Applications, 37(3), 2186-2196. http://dx.doi.org/10.1016/j.eswa.2009.07.065

Madu, C.N., Kuel, C.H. \& Madu, I.E. (2002). A hierarchic metric approach for integration of green issues in manufacturing: A paper recycling application. Fournal of Environmental Management, 64, 261-272. http:// dx.doi.org/10.1006/jema.2001.0498

Masui, K., Sakao, T., Kobayashi, M. \& Inaba, A. (2003). Applying quality function deployment to environmentally conscious design. International fournal of Quality and Reliability Management, 20(1), 90-106. http://dx.doi.org/10.1108/02656710310453836

McCarty, T., Jordan, M. \& Probst, D. (2011). Six Sigma for Sustainability: How Organizations Design and Deploy Winning Environmental Programs. McGraw-Hill. ISBN 978-0-07-175245-9.

Ozcelik, F. \& AvciOzturk, B. (2014). A research on barriers to sustainable supply chain management and sustainable supplier selection criteria. Dokuz Eylul Universitesi Sosyal Bilimeler Enstitusu dergisi, 16(2), 250-277. 
Petala, E., Wever, R., Dutilh, C., \& Brezet, H.C. (2010). The role of new product development briefs in implementing sustainability: a case study. Journal of Engineering Technology Management, 27(3-4), 172-182. http://dx.doi.org/10.1016/j.jengtecman.2010.06.004

Porter, M. \& van der Linde, C. (1995). Green and competitive: ending the stalemate. Harvard Business Review, 73(5), pp. 120-134.

Reyes, D.E.S. \& Wright, T.L. (2001). A design for the environment methodology to support an environmental management system. Integrated Manufacturing Systems, 12(5), 323-332. http://dx.doi.org/ 10.1108/EUM0000000005710

Robinson, C.J. \& Malhotra, M. K. (2005). Defining the concept of Supply Chain Quality Management and its relevant to academic and industrial practice. International fournal of Production Economics, 96, 315-337. http://dx.doi.org/10.1016/j.ijpe.2004.06.055

Sakao, T. (2007). A QFD-centred design methodology for environmentally conscious product design. International fournal of Production Research, 45(18), 4143-4162. http://dx.doi.org/10.1080/00207540701450179

Seuring, D. (2004). Industrial ecology, life cycles, supply chains differences and interrelations. Business Strategy and the Environment, 3(5), 306-319. http://dx.doi.org/10.1002/bse.418

Seuring, D. \& Muller, M. (2008). From a literature review to a conceptual framework for sustainable supply chain management. fournal of Cleaner Production, 16(15), 1699-1710. http://dx.doi.org/10.1016/j. jclepro.2008.04.020

Simchi-Levi, D. Kaminsky, P. \& Simchi-Levi, E. (2008). Designing \& Managing the Supply Chain: Concepts, Strategies \& Case Studies, Third Edition, McGraw-Hill, Irwin, NY, NY.

Sroufe, R.P. \& Melnyk, S.A. (2013). Developing Sustainable Supply Chains to Drive Value: Management Issues, Insights, Concepts and Tools. Business Expert Press. ISBN-13:978-1-60649-372-4.

Tague, N.R. (2004). The Quality Toolbox, Second Edition, ASQ Quality Press, Milwaukee, WI. 
Talib, F., Rahman, Z. \& Quereeshi, M.N. (2010). Pareto Analysis of Total Quality Management Factors Critical to Success for Service Industries. International Journal of Quality Research, 4(2), 155-168.

Talib, F. \& Rahman, Z. (2010). Critical Success Factors of TQM in Service Organizations: A Proposed Model. Service Marketing Quarterly, 31(2), 363-380. http://dx.doi.org/10.1080/15332969.2010.486700

Tan, K.C. (2001). A Framework of Supply Chain Management Literature. European fournal of Purchasing and Supply Management, 7(1), 39-48. http://dx.doi.org/10.1016/S0969-7012(00)00020-4

Utne, I.B. (2009). Improving eh environmental performance of the fishing fleet by use of quality function deployment (QFD). Fournal of Cleaner Production, 17, 724-731. http://dx.doi.org/10.1016/j.jclepro.2008.11.005

Vachon, S. \& Mao, Z. (2008). Linking supply chain strength to sustainable development: a country-level analysis. fournal of Cleaner Production, 16(15), pp. 1552-1560. doi:10.1016/j.jclepro.2008.04.012

Walmart Supplier Sustainabiltiy Assessment: 15 Questions for Suppliers. Accessed January 27, 2015, http://az204679.vo.msecnd.net/media/ documents/r_3863.pdf

Willard, B. (2012). The new sustainability advantage, $10^{\text {th }}$ Anniversary Edition. Canada: New Society Publishers.

World Commission on Environment and Development (WCED) (1987). Our Common Future. Oxford University Press. Oxford.

Wu, Z. \& Pagell, M. (2011). Balancing priorities: Decision-making in sustainable supply chain management. Fournal of Operations Management, 29, 577-590. http://dx.doi.org/10.1016/j.jom.2010.10.001

Zhang, Y., Wang, H.-P. \& Zhang, C. (1999). Green QFD-II: A life cycle approach for environmentally conscious manufacturing by integrating LCA and LCC into QFD matrices. International fournal of Production Research, 37(5), 1075-1091. http://dx.doi.org/10.1080/00207549919141 
56 The BRC Academy Journal of Business Vol. 6, No. 1

\section{Citation Information}

Fish, Lynn A. "Using TQM to Implement Sustainability in Supply Chain Management." The BRC Academy fournal of Business 6, no. 1 (2016): 3155. http://dx.doi.org/10.15239/j.brcacadjb.2016.06.01.ja02

\section{Web Appendix}

A web appendix for this paper is available at:

http://dx.doi.org/10.15239/j.brcacadjb.2016.06.01.wa02 